\title{
Introduction to the Healthcare Transformation Journal's Book Review Section and an Invitation to Book Reviewers
}

\author{
Ronald S. Weinstein, MD, FCAP, FATA* and Michael J. Holcomb, BS
}

\begin{abstract}
Each issue of the Healthcare Transformation Journal will include a book review on a topic related to healthcare transformation. There are three types of book reviews that will appear in Healthcare Transformation Journal: General Interest Book Reviews; Critical Book Reviews; and Scholar Book Reviews.
\end{abstract}

Each issue of the Healthcare Transformation Journal will include a book review on a topic related to healthcare transformation.

Book reviews published in professional research journals serve a special purpose. ${ }^{1-4}$ Professional research journals, by their very nature, serve primarily niche readerships. For example, although "robotics," "artificial intelligence," "automation" and "telehealth" have large cores of knowledge from the perspective of researchers immersed in those particular fields, each of these domains represents a tiny fraction of the much larger universe of accumulated knowledge. A goal of the Book Review section in Healthcare Transformation Journal is that of offering a guide to the journal's readership in expanding their intellectual horizons in an efficient manner. The book reviews will be on topics somehow linked to the topic "healthcare transformation," providing an information aggregating and filtering service for readers of Healthcare Transformation Journal. The majority of the books selected for review will have been screened by the critical book reviewers employed by their publishers. Occasionally, a self-published book might be reviewed if its potential interest and value to the readers of Healthcare Transformation Journal are sufficient.

A challenge for the Book Review Editor of Healthcare Transformation Journal will be to reconcile the "relatively narrow" scopes of the core topics selected for publication in research articles in Healthcare Transformation Journal and the many definitions for "healthcare transformation" in common usage or, more recently, newer definitions proposed by new waves of visionaries, subject matter experts, or even investigative reporters, who are paid to gather information and inform the public.

As a practical matter, many of the books selected for book reviews will provide readers with broad overviews, deep dives, or both, into pertinent subject matter on a wide range of current healthcare transformation-related topics and issues.

\section{Categories of Book Reviews}

In general, book reviews will fall into one of the three categories: (1) general interest book reviews, (2) critical book reviews, and (3) scholar book reviews. Typically, general interest book reviews announce that a new book, on a significant topic especially relevant to healthcare transformation, has become available. This type of review will highlight topics addressed in the book and might be authored by a journalist without special expertise in the particular subject matter addressed in the book, although special expertise is always more than welcome. At the other end of the book review spectrum, scholar book reviews will present substantive analysis and discussion of books by genuine experts in the relevant area of scholarship.

\section{General Interest Book Reviews}

The first category, the general interest book review, is essentially a news story announcing the publication of a new book. Often, a general interest book review appears at the leading edge of the book's public roll out by the book's publisher. The early appearance of the general interest book review may be part of the publisher's 
marketing campaign aimed at creating interest in a new book and maximizing the size and scope of its market downstream. Healthcare Transformation Journal could choose to publish three or four general interest book reviews on related topics in clusters, in a single issue. General interest book reviews are typically 150-200 words in length.

\section{Critical Book Reviews}

The next category, critical book reviews, is written for an informed audience by individuals with professional training related to the book's theme, who are also capable of achieving scientific rigor in their thinking. The critical book review will provide an introduction to the central themes covered by the book, a brief overview of the book's content, and mention of the quality of the writing and scholarship. Authors of critical book reviews should be accomplished experts in their own scholarly fields, and preferably authors of recently published highly acclaimed books on related themes. Name recognition in the field is another desirable attribute for the authors of critical book reviews. Critical book reviews are longer than general interest book reviews. A book selected for critical review might have been previously reviewed, often by a different reviewer, in either a premier commercial publication, such as in the New York Times' Book Review Section, or in the Review section of the Saturday Wall Street Journal, or in a large circulation professional journal such as the Journal of the American Medical Association. If such a book would be of special interest to our highly focused Healthcare Transformation Journal's readership, we might invite a qualified specialist from our academic community to write a second review of the same book, and request that the book review writer focus attention on the specific areas of the book with greatest relevance to the healthcare transformation theme. Critical book reviews are up to 300 words in length.

\section{Scholar Book Reviews}

Scholar book reviews are "book reviews written for scholars by scholars." A scholar book review will include brief summaries of the book's individual chapters, a critical analysis of the book's content, mention of the book's potential impact on the field of scholarship it represents, and a commentary on the book's relationship to other publications in the field. Credentials of the scholarly book's author, including mention of major accomplishments, may be included. Comparisons may be made with other books dealing with the same core content, and their relative merits. Writers of our scholar book reviews will typically have a track record in research and professional authoring in an area of scholarship directly related to the subject matter in the book being reviewed. Scholar book reviews are $\sim 500$ words in length.

All three categories of book reviews will appear in the Healthcare Transformation Journal's Book Review section from time to time.

\section{Open Invitation to Potential Book Reviewers}

We encourage interested book review authors to contact us directly and request to have their names added to our list of potential book reviewers. Please include a copy of your curriculum vitae for our files so we will know your current range of interests. We anticipate that publishers will furnish books directly to Healthcare Transformation Journal for distribution to our book review writers.

\section{Assignments of Books to Reviewers}

Book reviewers will be recruited through one of the following three ways: (1) from a pool of reviewers with special expertise as scholars on the subject matter covered in a recently published book, (2) on recommendation of a prequalified book reviewer who nominates a book for inclusion in the Healthcare Transformation Journal's Book Review section and also offers to write the book review, or (3) invitation by the Book Review Editor to a Healthcare Transformation Journal Editorial Board member to author a book review.

\section{Author Disclosure Statement}

No competing financial interests exist.

\section{Funding Information}

No funding was received for this article.

\section{References}

1. King LS. The book review. JAMA. 1968; 205:91-92.

2. Ackerman $A B$. Are book reviews in a medical journal worthy? (Editorial). Am J Dermatopathol. 1986; 8:461.

3. Lee $A D$, Green $B N$, Johnson $C D$, et al. How to write a scholarly book review for publication in a peer-reviewed Journal. A review of the literature. J Chiropr Educ. 2010; 24:57-69.

4. Worsham L. The endangered scholarly book review. Chronicle of Higher Education. (Advice). https://www.chronicle.com/article/TheEndangered-Scholarly-Book/131361 (Last accessed on Auguts 26, 2019). 